Int. J. Dev. Biol. 54: 1481-1486 (2010)

doi: $10.1387 /$ ijdb. 103111 ts

\title{
Inter-species transplantation and migration of primordial germ cells in cyprinid fish
}

\author{
TAIJU SAITO*,1,2, RIE GOTO-KAZETO'1, TAKAFUMI FUJIMOTO², YUTAKA KAWAKAMI"1, \\ KATSUTOSHI ARAI ${ }^{2}$ and ETSURO YAMAHA ${ }^{1}$ \\ ${ }^{1}$ Nanae Fresh Water Laboratory, Field Science Center for Northern Biosphere, Hokkaido University, Nanae, \\ Japan and ${ }^{2}$ Laboratory of Aquaculture Genetics \& Genomics, Faculty of Fisheries Sciences, Hokkaido \\ University, Hakodate, Japan
}

\begin{abstract}
Primordial germ cells (PGCs) are the only cells in developing embryos that can transmit genetic information to the next generation. PGCs therefore have considerable potential value for gene banking and cryopreservation, particularly via production of donor gametes using germ-line chimeras. In some animal species, including teleost fish, the feasibility of using PGC transplantation to obtain donor-derived offspring, within and between species, has been demonstrated. Successful use of PGC transplantation to produce germ-line chimeras is absolutely dependent on the migration of the transplanted cells from the site of transplantation to the host gonadal region. Here, we induced germ-line chimeras between teleost species using two different protocols: blastomere transplantation and single PGC transplantation. We evaluated the methods using the rate of successful migration of transplanted PGCs to the gonadal region of the host embryo. First, we transplanted blastomeres from zebrafish, pearl danio, goldfish, or loach into blastula-stage zebrafish embryos. Some somatic cells, derived from donor blastomeres, were cotransplanted with the PGCs and formed aggregates in the host embryos; a low efficiency of PGC transfer was achieved. Second, a single PGC from the donor species was transplanted into a zebrafish embryo. In all inter-species combinations, the donor PGC migrated toward the gonadal region of the host embryo at a comparatively high rate, regardless of the phylogenetic relationship of the donor and host species. These transplantation experiments showed that the mechanism of PGC migration is highly conserved beyond the family barrier in fish and that transplantation of a single PGC is an efficient method for producing inter-species germ-line chimeras.
\end{abstract}

KEY WORDS: germ-line chimera, primordial germ cell (PGC), xenogenesis, zebrafish, transplantation

\section{Introduction}

The function of germ cells is to transmit genetic information from one generation to the next. The role of somatic cells is to provide the conditions necessary to enable the germ cells to complete gametogenesis. Transplantation of germ cells from a donor into a genetically different host produces a germ-line chimera. This concept underlies recent attempts to obtain viable gametes from germ-line chimeras (Brinster and Zimmermann, 1994; Brinster and Avarbock, 1994; Clouthier et al., 1996; Yamaha et al., 2001; Yamaha et al., 2003; Takeuchi et al., 2001; Takeuchi et al., 2003; Takeuchi et al., 2004; Okutsu et al., 2006; Saito et al., 2008).

Germ-line chimeras have been used to obtain offspring that originate from cultured cells or donor germ cells. In the mouse, embryonic stem cells are able to differentiate into the germ-line when transplanted into the blastocoel of a host embryo; a gene knock-out technology has been developed using cell lines and this transplantation protocol. The transplantation of male germ cells into an adult testis has also been established and donorderived sperm can be successfully produced, even if germ cells are from a different species to the host (Clouthier et al., 1996; Ogawa et al., 1999; Ohta et al., 2003; Chuma et al., 2005; van de Lavoir et al., 2006). In birds, methods for collecting PGCs from the blood of embryos and then transplanting the cells into a host

Abbreviations used in this paper: PGCs, primordial germ cells; BT, blastomere transplantation; SPT, single primordial germ cell transplantation.

\footnotetext{
*Address correspondence to: Taiju Saito. Nanae Fresh Water Laboratory, Field Science Center for Northern Biosphere, Hokkaido University, 2-9-1 Sakura-machi, Nanae, Hokkaido 041-1105, Japan. Fax: +81-138-65-2239. e-mail: taiju@hokudai-nanae.jp
} 


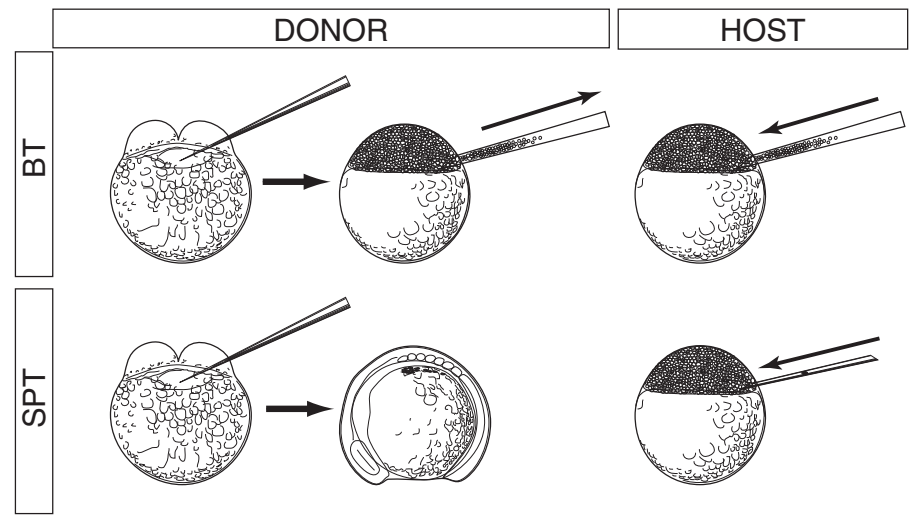

Fig. 1. Schematic illustration of transplantation of primordial germ cells (PGCs). (BT) In blastomere transplantation, the marginal region of the blastodisc is aspirated into a microneedle and then transplanted into a host blastula stage embryo.In this study, GFP-nos1 3'UTR mRNA and tetramethyl-rhodamine were injected into host embryos to enable visualization of PGCs and somatic cells, respectively. (SPT) In single PGC transplantation, GFP-nos1 3'UTR mRNA is injected into the fertilized egg to enable visualization of PGCs. A cell with GFP labeling at the somitogenesis period is transplanted into the host blastula embryo under the fluorescence microscope.

embryo have been established and used to obtained offspring that originated from the transplantation donor (Yasuda et al., 1992; Tajima et al., 1993).

The production of gametes from germ-line chimeras has recently been recognized and exploited as an effective method for breeding of target strains or species in fishes (reviewed by Yoshizaki et al., 2004; Okutsu et al., 2006; Yamaha et al., 2007). Two problems still need to be solved for successful production of germ-line chimeras in fish: immunological rejection by the host; and, delivery of the donor germ cells into the host gonad. In salmonids, these problems can be surmounted by transplanting germ-line cells into the body cavity of a hatched embryo. The transplanted germ cells in the resulting chimeras migrate along the wall of the body cavity toward the gonadal ridge and become located there (Takeuchi et al., 2003; Takeuchi et al., 2004; Okutsu et al., 2006; Kobayashi et al., 2007). Subsequently, gonadal somatic cells of the host surround the transplanted germ cells; this reorganization may disable any later immunological rejection of the germ cells. It has been shown in species such as zebrafish that germ cells can be transplanted at early embryonic stages (Saito et al., 2008). In this study, donor PGCs were visualized with GFP by injecting GFP-nos1 3'UTR mRNA into one- to four-cell stage embryos. The embryos were allowed to develop to the somitogenesis stage and a single GFP-positive PGC was picked up with a microneedle and transplanted into a host blastula stage embryo under a fluorescence stereomicroscope. In many host embryos, the transplanted PGCs successfully migrated toward gonadal anlage. These transplantation experiments showed that viable sperm could be produced in germ-line chimeras between different species, that is, xenogenesis was feasible across species, genus, and family barriers (Saito et al., 2008). In similar fashion, it has been reported that intra-specific germ-line chimeras can be produced by transplanting blastomeres at the blastula stage (Lin et al., 1992; Ciruna et al., 2002; Yamaha et al., 2001; Yamaha et al., 2003; Takeuchi et al., 2001). This protocol has not, however, been used to produce germ-line chimeras for xenogenesis.

Here, we compare the relative efficiency of these two PGC transplantation methods, i.e., single PGC transplantation (SPT) and blastomere transplantation (BT), for generating xenogeneic germ-line chimeras in fish (Fig. 1). We chose to use Cypriniformes species in this study because this group includes zebrafish, in which developmental mechanisms have been studied over many years, and also many other species of relevance to inland freshwater aquaculture. We used zebrafish (Danio rerio), pearl danio (Danio albolineatus), and goldfish (Carassius auratus), all of the family Cyprinidae, and loach (Misgurnus anguillicaudatus) of the family Cobitidae as donors, and zebrafish as the host. In this way, we were able to investigate the influence of genetic relationship between the species on the efficiency of PGC transfer.

\section{Results}

\section{Localization of somatic cells and PGCs in BT chimeras}

Blastomeres were aspirated from zebrafish, pearl danio, goldfish, or loach blastulas and transplanted into zebrafish blastulas. When the blastomeres were transplanted between embryos of the same species, i.e., zebrafish to zebrafish, the transplanted cells were intermingled and widely scattered through the resultant embryo during development and showed no evidence of aggregation at $24 \mathrm{hpf}$ (Fig. 2A). Donor-derived GFP-positive PGCs were observed in the gonadal region of $8.97 \%$ of the intra-specific embryos (Table 1). The proportions of inter-specific chimeras with transplanted PGCs in gonadal region were also estimated: pearl danio to zebrafish, $6.25 \%$; goldfish to zebrafish, $7.29 \%$; and, loach to zebrafish, $1.45 \%$ (Table 1). Transplanted xenogeneic cells tended to aggregate in the host embryos and these aggregations became tighter as the phylogenetic relationship became more divergent (Fig. 2 C,D). Moreover, in some chimeras, it seems that migration of the transplanted PGCs was negatively

TABLE 1

\section{EFFICIENCY OF PGC TRANSFER IN INTER-SPECIES BLASTOMERE-TRANSPLANTATION CHIMERAS}

\begin{tabular}{lcccc}
$\begin{array}{l}\text { Donor/host } \\
\text { combination }\end{array}$ & $\begin{array}{c}\text { Total no. of } \\
\text { chimeras }\end{array}$ & $\begin{array}{c}\text { No. of chimeras } \\
\text { developed normally }\end{array}$ & $\begin{array}{c}\text { No. of chimeras } \\
\text { to which donor } \\
\text { PGCs were }\end{array}$ & $\begin{array}{c}\text { No. of chimeras } \\
\text { transferred (\%) } \\
\text { PGCs at gonadal } \\
\text { region (\%) }\end{array}$ \\
\hline Zebrafish/zebrafish & 90 & 78 & $8(10.26)$ & $7(8.97)$ \\
Pearl danio/zebrafish & 63 & 61 & $4(6.25)$ & $4(6.25)$ \\
Goldfish/zebrafish & 131 & 96 & $8(8.33)$ & $7(7.29)$ \\
Loach/zebrafish & 91 & 69 & $9(13.04)$ & $1(1.45)$ \\
\hline
\end{tabular}

TABLE 2

\section{DIFFERENCE IN MIGRATORY ACTIVITY OF PGCs FROM DONORS AT DIFFERENT DEVELOPMENTAL STAGES}

\begin{tabular}{lcccc} 
Stage & $\begin{array}{c}\text { Total no. of } \\
\text { chimeras }\end{array}$ & $\begin{array}{c}\text { No. of chimeras } \\
\text { developed normally }\end{array}$ & $\begin{array}{c}\text { No. of chimeras in } \\
\text { which donor PGC was } \\
\text { observed at 2 dpf (\%) }\end{array}$ & $\begin{array}{c}\text { No. of chimeras with } \\
\text { PGC located at } \\
\text { gonadal region (\%) }\end{array}$ \\
\hline $10-15$ somite & 78 & 70 & $60(85.7)$ & $21(30.0)$ \\
$21-25$ somite & 108 & 89 & $75(84.3)$ & $9(10.1)$ \\
Prim-5 & 167 & 131 & $113(86.3)$ & $7(5.3)$ \\
Prim-15 & 102 & 89 & $77(86.5)$ & $4(4.5)$ \\
\hline
\end{tabular}



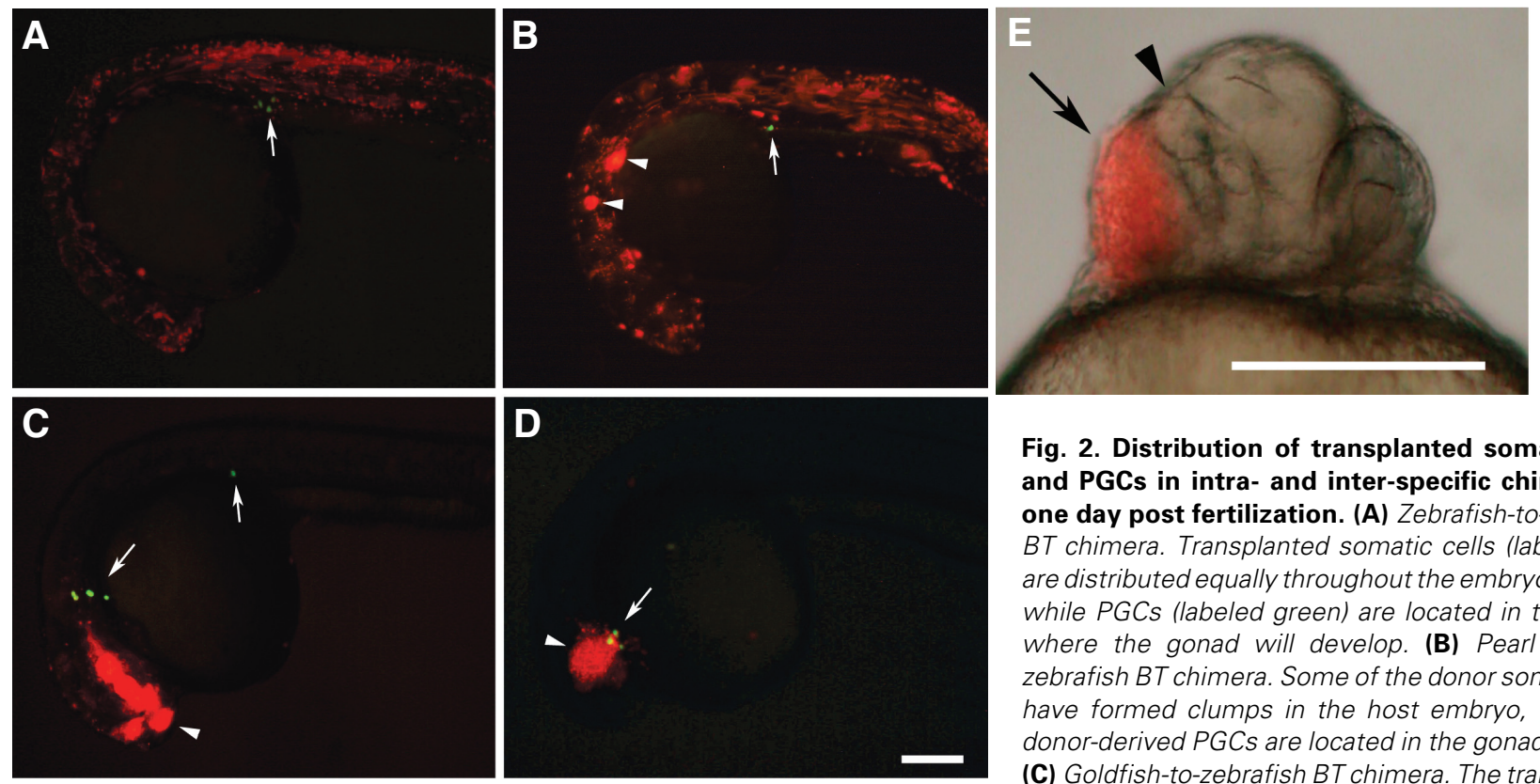

Fig. 2. Distribution of transplanted somatic cells and PGCs in intra- and inter-specific chimeras at one day post fertilization. (A) Zebrafish-to-zebrafish BT chimera. Transplanted somatic cells (labeled red) are distributed equally throughout the embryonic body, while PGCs (labeled green) are located in the region where the gonad will develop. (B) Pearl danio-tozebrafish BT chimera. Some of the donor somatic cells have formed clumps in the host embryo, while the donor-derived PGCs are located in the gonadal region. (C) Goldfish-to-zebrafish BT chimera. The transplanted somatic cells have formed large aggregations and some of the PGCs are located in proximity to the somatic cells. (D) Loach-to-zebrafish BT chimera. The transplanted somatic cells are tightly aggregated around the embryonic head region and the PGCs are located close to the aggregation. (E) Loach-to-zebrafish BT chimera. In this chimera, the transplanted cells (arrow) localized around head region and disrupted development of optic structure of host embryo (arrowhead). Arrows in A-D indicate the donor-derived PGCS. Arrowheads in A-D indicate the donor cell aggregations. Scale bar indicates $500 \mu \mathrm{m}$.

influenced by the aggregated somatic cells. That is, in these chimeras, donor PGCs tended to be localized close to the aggregations (Fig. 2 C, D). Additionally, aggregation of goldfish or loach cells in inter-specific chimeras also disturbed the development of the host embryo. Abnormal embryos were increasingly observed as the phylogenic relationship become more divergent. This developmental disruption was apparent in structures where the transplanted cells localized, for example, neural tube, optic structures, otic vesicle, and somites, although the majority of embryos nevertheless survived to the fry stage at least. In many embryos, the transplanted cells tend to localize around the head region, especially at the optic structures (Fig. 2E).

\section{Optimum embryo developmental stage for SPT}

As mentioned above, the presence of co-transplanted somatic cells influenced both development of the host embryos and PGC migration. In addition, the transplantation method did not consistently produce germ-line chimeras. To exclude the influence of somatic cells while simultaneously ensuring that we transplanted PGCs, we isolated PGCs from embryos that had been injected with GFP-nos1 3'UTR mRNA to label the germ cells. We previously showed that a single PGC isolated from a 10-15-somite stage could migrate toward the gonadal region of a host embryo after transplantation (Saito et al., 2008). However, in the earlier study, we did not determine the optimal stage of donor embryo development for isolating PGCs for successful SPT. To investigate this point, we isolated zebrafish PGCs for transplantation from embryos at various stages of development:10-15-somite stage, 21-25-somite stage, prim-5 stage, prim-15 stage, and prim-25 stage. The PGCs were then transplanted into zebrafish blastula stage embryos as described earlier. The 10-15-somite embryo was the earliest stage at which PGCs could be reliably distinguished from somatic cells that possessed background GFP fluorescence. We found that the migration efficiency rate decreased as the donor embryos developed. Thus, a rate of $30 \%$ was obtained using 10-15 somite stage embryos, but only $3.6 \%$ for prim-25 stage embryos (Table 2). We conclude that PGCs at the 10-15-somite stage are the most suitable for use in production of SPT germ-line chimeras. The donor PGC localized at the gonadal region started to proliferate around 6 to $7 \mathrm{dpf}$ at the same time as the host PGCs, and occupied part of the gonad (Fig. 3 A-D).

\section{Migration rates of PGCs in inter-specific chimeras}

We compared PGC migration rates in inter-specific chimeras produced by the SPT method using donor PGCs from 10-15somite stage embryos of pearl danio, loach, or goldfish and zebrafish blastula embryos as the host. We found that the transplanted PGCs migrated toward and localized at the gonadal region of the zebrafish embryos at high rates. Interestingly, the migration rates for these species exceeded that obtained for intraspecific zebrafish SPT chimeras (Table 3). Our results show that PGCs derived from xenogeneic species can migrate under the guidance controls signals of the host embryo, and, moreover, that the efficiency of their migration is not related to the phylogenetic distance between the donor and host species.

\section{Discussion}

In the present study we compared the relative efficiency of two methods, BT and SPT, for producing xenogeneic germ-line chimeras between four cyprinid species, zebrafish, pearl danio, 

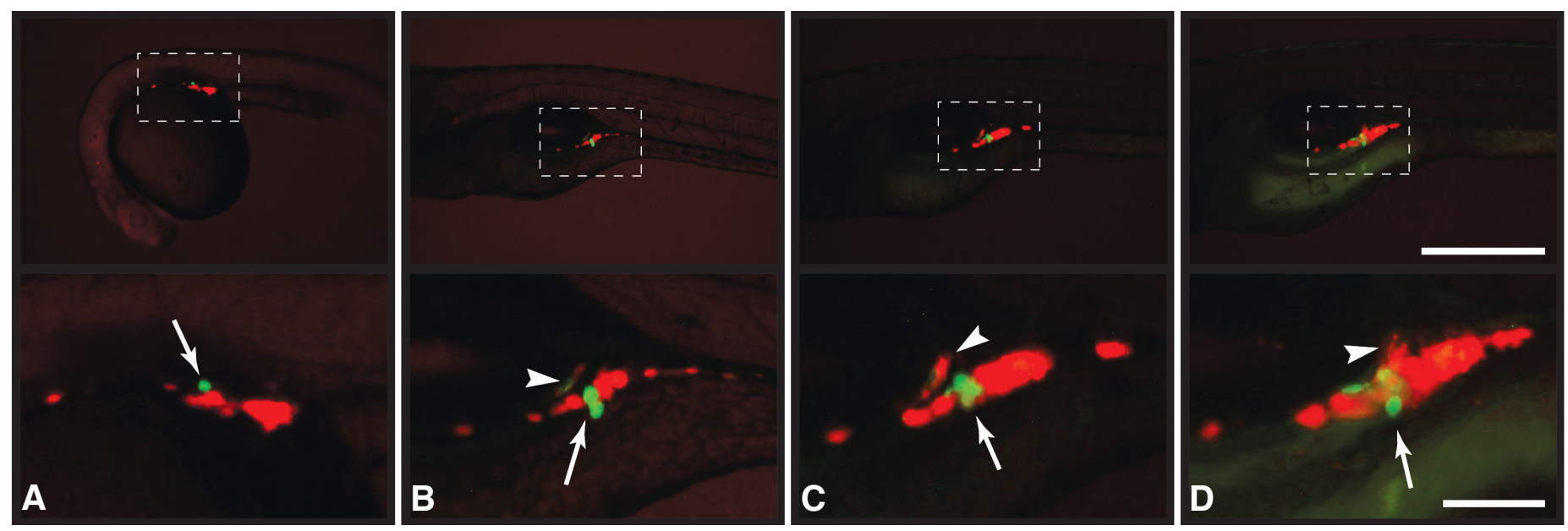

Fig. 3. The transplanted donor PGC localized at the gonadal region of the host embryo and started to proliferate at the same time as the host PGCs during gonadal development. Donor and host PGCs were labeled with GFP or RFP, respectively. The lower column showed an enlarged image of the boxed areas in the upper column. (A) 24 hpf chimera. A transplanted single PGC was localized, along with host PGCs, at the position where the gonad will develop. (B) 7 dpf chimera. A GFP-labeled PGC had divided once at this stage (arrow) and some of the host PGCs had also started to proliferate. PGCs still lay loosely at this stage. (C) $11 \mathrm{dpf}$ chimera. Both donor and host PGCs continued to proliferate and the PGCs began to form a tighter cluster than previously. (D) 14 dpf chimera. Both donor and host PGCs proliferated and became smaller. Arrows indicate a transplanted single donor PGC. Arrowheads indicate reflected fluorescence of labeled PGCs on gas bladder. Scale bar in upper column indicates $500 \mu \mathrm{m}$. Scale bar in lower column indicates $100 \mu \mathrm{m}$

goldfish, and loach. The species selected for study, zebrafish, pearl danio (both Cyprinidae, Danioninae), goldfish (Cyprinidae, Cyprinidae), and loach (Cobitidae), show a range of phylogenetic relatedness. The chosen host species, zebrafish, therefore differed from the donors at the species, sub-family and family levels.

\section{Aggregation of somatic cells in inter-specific BT chimeras}

Inter-specific BT chimeras routinely showed aggregations of donor cells in the host embryo, and the incidence of these clusters increased with the phylogenetic distance between the donor and host species. This behavior contrasted strongly with intra-specific chimeras in which donor cells freely intermingled with those of the host. One possible explanation for this disparity may come from reports in other species of differential cellular affinities caused by taxonomic differences (Maclennan, 1974; Giudice and Mutolo, 1970). When dissociated cells from different species are mixed together, the cells show "self" and "not-self" recognition during reaggregation resulting in the formation of two segregated clusters. The ability to discriminate self and not-self may result from the presence of different types and amounts of adhesion molecules on cell membranes. Some support for this interpretation comes from the observation that cells expressing different doses

TABLE 3

MIGRATION RATES OF PGCS TRANSPLANTED FROM DIFFERENT DONOR SPECIES INTO HOST ZEBRAFISH EMBRYOS

\begin{tabular}{ccccc} 
Donor species & $\begin{array}{c}\text { Total no. of } \\
\text { chimeras }\end{array}$ & $\begin{array}{c}\text { No. of chimeras } \\
\text { developed } \\
\text { normally }\end{array}$ & $\begin{array}{c}\text { No. of chimeras in } \\
\text { which donor PGC } \\
\text { was observed at } \\
\text { 2 dpf (\%) }\end{array}$ & $\begin{array}{c}\text { No. of chimeras with } \\
\text { PGC located at } \\
\text { gonadal region (\%) }\end{array}$ \\
\hline Zebrafish & 368 & 343 & $273(79.6)$ & $99(28.9)$ \\
Pearl danio & 272 & 209 & $139(66.5)$ & $84(40.2)$ \\
Goldfish & 381 & 263 & $235(89.4)$ & $167(63.5)$ \\
Loach & 119 & 102 & $87(85.3)$ & $44(43.1)$ \\
\hline
\end{tabular}

of cadherin are distributed accordingly along a gradient in the ovarian follicles of Drosophila (Godt and Tepass, 1998; GonzalezReyes and St Johnston, 1998). In light of these earlier studies, it is very likely that the aggregations of cells seen here in interspecific chimeras arose from a similar mechanism.

\section{Single PGC transplantation and migratory activity of PGCs during embryonic development}

We showed here that the age of the embryo from which PGCs were collected for SPT affected the likelihood of the PGCs successfully migrating to the gonadal region. The best results were obtained using 10-15-somite donor embryos. Overall, chimeric embryos produced by the SPT method had a higher rate of PGC migration to the gonadal region (approximately $30 \%$ ) than those from the BT method (approximately $9 \%$ ). The higher rate in the SPT protocol is achieved despite the requirement to inject mRNA into donor fertilized eggs in order to be able to identify PGCs at subsequent embryonic stages.

The result of this experiment showed that the migratory activity of PGCs decreased as the development of donor embryos progressed. This observation suggested that the migratory activity of PGCs is controlled autonomously and, moreover, that the somatic cells that guide PGCs to the gonadal region could not restore this activity. In this connection, it has been shown that there is a reorganization of granules and an altered pattern of gene expression in PGCs during embryonic development in zebrafish (Strasser et al., 2008).

Interestingly, our inter-specific transplantation experiments demonstrated that the migration rates of transplanted PGCs did not depend on the phylogenetic relationship between the donor species and zebrafish. The rates of PGC migration in the zebrafish host were high and ranged in the order goldfish, loach, pearl danio, and zebrafish. This result suggests that the migratory activity of PGCs in each species lasts for different lengths of time. 


\section{Comparison of the two transplantation methods}

In this study, we compared the relative abilities of two methods, SPT and BT, to produce germ-line chimeras between species. Our results clearly showed that the SPT method was significantly more effective than the BT approach due to its higher germ-line transmission and lower damage to the host embryos. Moreover, the technique does not require large numbers of donor embryos. It is known that fish species have dozens of PGCs in segmentation period embryos (Saito et al., 2006), and, in principle, it should be feasible to transplant these cells to the commensurate number of host embryos. This aspect would be particularly advantageous for production of xenogeneic germ-line chimeras of endangered species that spawn only small amounts of precious eggs and sperm, such as the Japanese bitterling, which spawns a few eggs into the mantle cavity of a mussel that serves as a surrogate mother. In addition, an SPT chimera can provide novel conditions for studying germ cells, that is, a situation in which germ cells are completely replaced without contamination by donor-derived somatic cells. In this study, the transplanted PGC started to proliferate at the same developmental age as host PGCs, i.e., at 6 to 7 $\mathrm{dpf}$ and then occupied part of the gonad. Our results clearly showed that, after SPT, a single transplanted PGC could proliferate and contribute to a developing gonad with an endogenous germ cell population. This observation suggests a possible means for tracing the fate of transplanted PGCs in adult fish when PGCs with a genetic marker, such as in a transgenic line, are used. By contrast, it is not possible with the BT method to ensure the transplantation of PGCs into each host embryo, and it is also difficult to produce large numbers of chimeras from a limited supply of donor embryos.

SPT does have the drawbacks that it is necessary to visualize PGCs by injecting a specific mRNA and that it requires use of a fluorescence microscope for the transplantation step, while BT does not require these procedures. In that regard, BT does have an advantage over SPT. BT will be of use for producing chimeras between the same species, strains, or related species, that is, in situations when the number of donor embryos is not a limiting factor. Ciruna et al. (2002) have already reported production of embryos carrying a maternal zygotic mutant by blastomere transplantation in zebrafish.

\section{Materials and Methods}

\section{Preparation of embryos}

Zebrafish were kept in the Nanae Fresh Water Laboratory, Hokkaido University and maintained at $26 \sim 28^{\circ} \mathrm{C}$ under a 16 hour light / 8 hour dark photoperiod. Fertilized eggs were obtained during the light period through natural mating: one female and two males were placed together in a 10 liter fish tank at $26 \sim 28^{\circ} \mathrm{C}$. Embryos were dechorionated with $0.1 \%$ trypsin (DIFCO) and $0.002 \%$ actinase E (KAKEN) in Ringer's culture solution (128 mM NaCl, $2.8 \mathrm{mM} \mathrm{KCl}, 1.8 \mathrm{mM} \mathrm{CaCl}$ ). Dechorionated embryos were cultured individually at $28.5^{\circ} \mathrm{C}$ in 96 -well plates (Greiner) in Ringer's culture solution containing $0.01 \%$ penicillin and $0.01 \%$ streptomycin, and later transferred to 24-well plates (Greiner) containing a modified culture solution (1.8 mM CaCl2, $1.8 \mathrm{mM} \mathrm{MgCl}$ ) with penicillin/streptomycin as above. The stages of embryonic development were identified according to Kimmel et al., 1995.

Pearl danio was kept at the Nanae Fresh-Water Laboratory and embryos were obtained as for zebrafish. Dechorionation and culture methods were also identical to those of zebrafish. The developmental stages of pearl danio have not yet been described. Therefore, staging of the embryos was accomplished on the basis of numbers of blastomeres and somites, and the extent of epiboly.

The loach used in this study were obtained from the Loach Farming Cooperation of Kitamura, Iwamizawa, Hokkaido, during the spawning season (June to August). Fertilization, dechorionation and culture of loach embryos were carried out as described by Fujimoto et al. (2004). The stage of embryo development was identified according to Fujimoto et al. (2006).

Goldfish were kept in the Nanae Fresh Water Laboratory, Hokkaido University. Embryos were obtained using the method described by Yamaha and Yamazaki (1993). Goldfish developmental stages were determined using the criteria listed by Yamaha et al. (1999) and Kajishima (1960). Dechorionation and culture methods were as described by Yamaha et al. (1986) and Otani et al. (2002), respectively.

\section{Construction and synthesis of mRNA}

Capped sense GFP-nos1 3'UTR RNA (Köprunner et al., 2001) was synthesized in vitro using the mMESSENGER MACHINE kit (Ambion).

\section{Microinjection of $m R N A$ and tracer dye}

For blastomere transplantation (BT), GFP-nos1 3'UTR mRNA and 5\% tetramethyl-rhodamine-lysin (fluoro-ruby; Molecular Probes) in $0.2 \mathrm{M} \mathrm{KCl}$ were co-injected into fertilized fish eggs at the one- to two-cell stage in order to visualize the donor cells. Rhodamine- and GFP-fluorescence was detected using an Olympus SZ-12 or Leica MZ-12 fluorescence stereomicroscope.

For single PGC transplantation (SPT), donor eggs were injected with GFP-nos1 3'UTR mRNA at the 2- to 4-cell stage. To observe PGC proliferation in SPT chimeras, GFP-nos1 3'UTR and RFP-nos1 3'UTR mRNA were injected into donor and host eggs, respectively.

\section{Transplantation}

Two transplantation methods, BT and SPT, were used here to produce germ line chimeras (Fig. 1). BT was performed at the blastula stage. About 50 to 100 blastomeres, labeled with RNA and fluorescent tracer, from the marginal region of the donor embryo were aspirated into a glass microneedle connected to a microinjector (CellTram oil; Eppendorf), and transplanted into the host blastoderm. SPT was performed as described by Saito et al. (2008). GFP-positive PGCs were dissociated from labeled somitogenesis stage embryos using $1 \%$ citric acid trisodium and $0.1 \%$ collagenase (Wako) or trypsin (Defco) in Ringer's solution and by pipetting. The dissociated cells were transferred into a $120 \mathrm{~mm}$ glass dish filled with $5 \%$ FBS (Gemini Bio-Products) in Ringer's solution containing 0.01\% penicillin and $0.01 \%$ streptomycin. Isolated PGCs were identified as GFPpositive cells and aspirated into a glass microneedle under a fluorescence stereomicroscope. A single PGC was transplanted into the marginal region of the blastodisc of each blastula stage zebrafish embryo. Migration efficiency was calculated as the number of embryos with PGCs located at the gonadal region divided by the number of embryos that developed normally at $24 \mathrm{hpf}$ (hours post fertilization). A minimum of 20 chimeras were produced in each experiment. The transplantation experiments were performed at least three times for each experimental group and the average migration efficiency was calculated from the sum of these experiments. Chimeric embryos were observed and photographed using a Leica MZ16F fluorescence stereomicroscope equipped with a digital camera (Leica DFC300FX). Images of the embryos were obtained using the appropriate filters for GFP and rhodamine fluorescence and were merged into a single image using Adobe Photoshop CS3 software.

\section{Ethics}

This study was carried out in accordance with Guide for the Care and Use of Laboratory Animals in Hokkaido University and Field Science Center for Northern Biosphere, Hokkaido University. 


\section{Acknowledgements}

We thank Mr. Shizuo Kimura, Ms. Misae Takagi, and the members of Nanae Fresh Water Laboratory, Field Science Center for Northern Biosphere, Hokkaido University for advice and help with the breeding of the fish. This study was supported by grants from the Bio-oriented Technology Research Advancement Institution (BRAIN) of Japan.

\section{References}

BRINSTER, R.L. AND AVARBOCK, M.R. (1994). Germline transmission of donor haplotype following spermatogonial transplantation. Proc Natl Acad Sci USA 91: 11303-11307.

BRINSTER, R.L. AND ZIMMERMANN, J.W. (1994). Spermatogenesis following male germ-cell transplantation. Proc Natl Acad Sci USA 91: 11298-11302.

CHUMA, S., KANATSU-SHINOHARA, M., INOUE, K., OGONUKI, N., MIKI, H., TOYOKUNI, S., HOSOKAWA, M., NAKATSUJI, N., OGURA, A. AND SHINOHARA, T. (2005) Spermatogenesis from epiblast and primordial germ cells following transplantation into postnatal mouse testis. Development 132: 117-122.

CIRUNA, B., WEIDINGER, G., KNAUT, H., THISSE, B., THISSE, C., RAZ, E. AND SCHIER, A.F. (2002). Production of maternal-zygotic mutant zebrafish by germline replacement. Proc Natl Acad Sci USA 99: 14919-14924.

CLOUTHIER, D.E., AVARBOCK, M.R., MAIKA, S.D., HAMMER, R.E. AND BRINSTER, R.L. (1996). Rat spermatogenesis in mouse testis. Nature 381: 418-421.

FUJIMOTO, T., KATAOKA, T., OTANI, S., SAITO, T., AITA, T., YAMAHA, E. AND ARAI, K. (2004). Embryonic stages from cleavage to gastrula in the loach Misgurnus anguillicaudatus. Zoolog Sci 21: 747-755.

FUJIMOTO, T., KATAOKA, T., SAKAO, S., SAITO, T., YAMAHA, E. AND ARAI, K (2006). Developmental stages and germ cell lineage of the loach (Misgurnus anguillicaudatus). Zoolog Sci 23: 977-989.

GIUDICE, G. AND MUTOLO, V. (1970). Reaggregation of dissociated cells of sea urchin embryos. Adv Morphog 8: 115-158.

GODT, D. AND TEPASS, U. (1998). Drosophila oocyte localization is mediated by differential cadherin-based adhesion. Nature 395: 387-391.

GONZALEZ-REYES, A. AND ST JOHNSTON, D. (1998). The Drosophila AP axis is polarised by the cadherin-mediated positioning of the oocyte. Development 125: $3635-3644$

KAJISHIMA, T. (1960). The normal developmental stage of the goldfish, Carassius auratus. Japan J Ichthyol 8: 20-28

KIMMEL, C.B., BALLARD, W.W., KIMMEL, S.R., ULLMANN, B. AND SCHILLING, T.F. (1995). Stages of embryonic development of the zebrafish. Dev Dyn 203: 253-310.

KOBAYASHI, T., TAKEUCHI, Y., TAKEUCHI, T. AND YOSHIZAKI, G. (2007). Generation of viable fish from cryopreserved primordial germ cells. Mol Reprod Dev 74: 207-213.

KÖPRUNNER, M., THISSE, C., THISSE, B. AND RAZ, E. (2001). A zebrafish nanos-related gene is essential for the development of primordial germ cells. Genes Dev 15: 2877-2885.

LIN, S., LONG, W., CHEN, J. AND HOPKINS, N. (1992). Production of germ-line chimeras in zebrafish by cell transplants from genetically pigmented to albino embryos. Proc Natl Acad Sci USA 89: 4519-4523.

MACLENNAN, A.P. (1974). The chemical bases of taxon-specific cellular reaggregation and «self»-»not-self» recognition in sponges. Arch Biol (Liege) 85: 53-90.

OGAWA, T., DOBRINSKI, I., AVARBOCK, M.R. AND BRINSTER, R.L. (1999). Xenogeneic spermatogenesis following transplantation of hamster germ cells to mouse testes. Biol Reprod 60: 515-521.

OHTA, H., TOHDA, A. AND NISHIMUNE, Y. (2003). Proliferation and differentiation of spermatogonial stem cells in the w/wv mutant mouse testis. Biol Reprod 69:
1815-1821.

OKUTSU, T., SUZUKI, K., TAKEUCHI, Y., TAKEUCHI, T. AND YOSHIZAKI, G. (2006). Testicular germ cells can colonize sexually undifferentiated embryonic gonad and produce functional eggs in fish. Proc Natl Acad Sci USA 103: 27252729.

OKUTSU, T., YANO, A., NAGASAWA, K., SHIKINA, S., KOBAYASHI, T., TAKEUCHI, Y. AND YOSHIZAKI, G. (2006). Manipulation of fish germ cell: visualization, cryopreservation and transplantation. J Reprod Dev 52: 685-693.

OTANI, S., MAEGAWA, S., INOUE, K., ARAI, K. AND YAMAHA, E. (2002). The germ cell lineage identified by vas-mRNA during the embryogenesis in goldfish. Zoolog Sci 19: 519-526.

SAITO, T., FUJIMOTO, T., MAEGAWA, S., INOUE, K., TANAKA, M., ARAI, K. AND YAMAHA, E. (2006). Visualization of primordial germ cells in vivo using GFPnos1 3'UTR mRNA. Int J Dev Biol 50: 691-699.

SAITO, T., GOTO-KAZETO, R., ARAI, K. AND YAMAHA, E. (2008). Xenogenesis in teleost fish through generation of germ-line chimeras by single primordial germ cell transplantation. Biol Reprod 78: 159-166.

STRASSER, M.J., MACKENZIE, N.C., DUMSTREI, K., NAKKRASAE, L.I., STEBLER, J. AND RAZ, E. (2008). Control over the morphology and segregation of Zebrafish germ cell granules during embryonic development. BMC Dev Biol 8: 58.

TAJIMA, A., NAITO, M., YASUDA, Y. AND KUWANA, T. (1993). Production of germ line chimera by transfer of primordial germ cells in the domestic chicken (Gallus domesticus). Theriogenology 40: 509-519.

TAKEUCHI, Y., YOSHIZAKI, G. AND TAKEUCHI, T. (2001). Production of germline chimeras in rainbow trout by blastomere transplantation. Mol Reprod Dev 59: $380-389$

TAKEUCHI, Y., YOSHIZAKI, G. AND TAKEUCHI, T. (2003). Generation of live fry from intraperitoneally transplanted primordial germ cells in rainbow trout. Biol Reprod 69: 1142-1149.

TAKEUCHI, Y., YOSHIZAKI, G. AND TAKEUCHI, T. (2004). Surrogate broodstock produces salmonids. Nature 430: 629-630.

VAN DE LAVOIR, M.C., DIAMOND, J.H., LEIGHTON, P.A., MATHER-LOVE, C., HEYER, B.S., BRADSHAW, R., KERCHNER, A., HOOI, L.T., GESSARO, T.M., SWANBERG, S.E., DELANY, M.E. AND ETCHES, R.J. (2006). Germline transmission of genetically modified primordial germ cells. Nature 441: 766-769.

YAMAHA, E., KAZAMA-WAKABAYASHI, M., OTANI, S., FUJIMOTO, T. AND ARAI, K. (2001). Germ-line chimera by lower-part blastoderm transplantation between diploid goldfish and triploid crucian carp. Genetica 111: 227-236.

YAMAHA, E., MIZUNO, T., MATSUSHITA, K. AND HASEBE, Y. (1999). Developmental staging in goldfish during the pre-gastrula stage. Nippon Suisan Gakkaishi 65: 709-717.

YAMAHA, E., MURAKAMI, M., HADA, K., OTANI, S., FUJIMOTO, T., TANAKA, M. SAKAO, S., KIMURA, S., SATO, S. AND ARAI, K. (2003). Recovery of fertility in male hybrids of a cross between goldfish and common carp by transplantation of PGC (primordial germ cell)-containing graft. Genetica 119: 121-131.

YAMAHA, E., SAITO, T., GOTO-KAZETO, R. AND ARAI, K. (2007). Developmental biotechnology for aquaculture, with special reference to surrogate production in teleost fishes. J Sea Res 58: 8-22.

YAMAHA, E., USUI, K., ONOZATO, H. AND HAMADA, K. (1986). A method for dechorionation in goldfish, Carassius auratus. Bull Japan Soc Sci Fish 52: 291 298.

YAMAHA, E. AND YAMAZAKI, F. (1993). Electrically fused-egg induction and its development in the goldfish, Carassius auratus. Int J Dev Biol 37: 291-298.

YASUDA, Y., TAJIMA, A., FUJIMOTO, T. AND KUWANA, T. (1992). A method to obtain avian germ-line chimaeras using isolated primordial germ cells. J Reprod Fertil 96: 521-528

YOSHIZAKI, G., TAKEUCHI, Y., KOBAYASHI, T. AND TAKEUCHI, T. (2004) Primordial germ cells: A novel tool for fish bioengineering. Fish Physiol Biochem 28: $453-457$. 


\section{Further Related Reading, published previously in the Int. J. Dev. Biol.}

See our recent Special Issue Placenta edited by Joan S. Hunt and Kent L. Thornburg at: http://www.ijdb.ehu.es/web/contents.php?vol=54\&issue=2-3

In vitro germ cell differentiation during sex differentiation in a teleost fish Tohru Kobayashi

Int. J. Dev. Biol. (2010) 54: 105-111

Cloning and pattern of expression of the shiro-uo vasa gene during embryogenesis and its roles in PGC development Akimitsu Miyake, Taiju Saito, Tohru Kashiwagi, Daisuke Ando, Akitsugu Yamamoto, Tohru Suzuki, Norio Nakatsuji and Takako Nakatsuji Int. J. Dev. Biol. (2006) 50: 619-625

Visualization of primordial germ cells in vivo using GFP-nos1 3'UTR mRNA

Taiju Saito, Takafumi Fujimoto, Shingo Maegawa, Kunio Inoue, Minoru Tanaka, Katsutoshi Arai and Etsuro Yamaha Int. J. Dev. Biol. (2006) 50: 691-700

The formation of primordial germ cells from germline cells in spherical embryos derived from the blastodisc of 2-cell embryos in goldfish, Carassius auratus

Satoshi Otani, Tomoe Kitauchi, Taiju Saito, Suzu Sakao, Shingo Maegawa, Kunio Inoue, Katsutoshi Arai and Etsuro Yamaha Int. J. Dev. Biol. (2005) 49: 843-850

Cubozoan jellyfish: an Evo/Devo model for eyes and other sensory systems Joram Piatigorsky and Zbynek Kozmik Int. J. Dev. Biol. (2004) 48: 719-729

Primordial germ cell migration Kathleen Molyneaux and Christopher Wylie Int. J. Dev. Biol. (2004) 48: 537-543

Germ line development in fishes A K Braat, J E Speksnijder and D Zivkovic Int. J. Dev. Biol. (1999) 43: 745-760

5 yr ISI Impact Factor $(2008)=3.271$

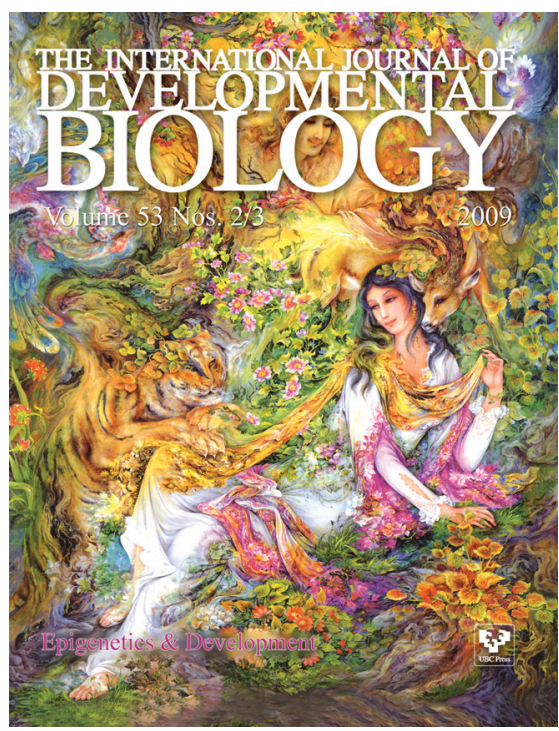

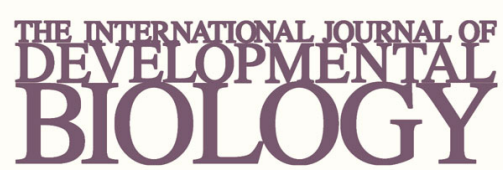

Volume 54 Nos. 6/7
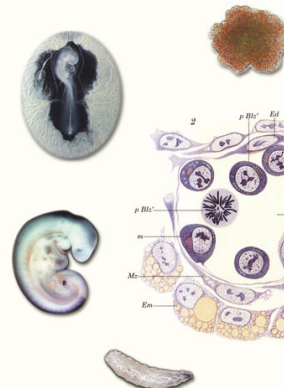

Special Issue

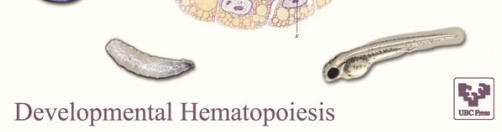

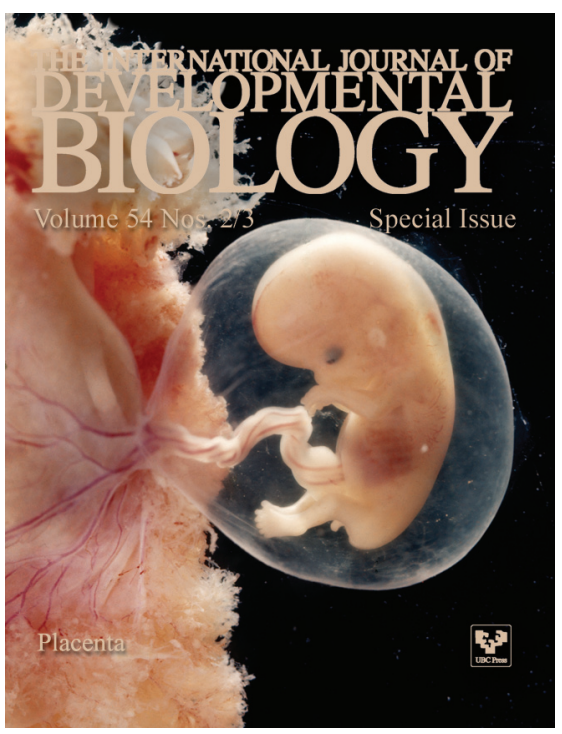

